\title{
PENELITIAN KUAT UJI TEKAN BETON DENGAN MEMANFAATKAN LIMBAH BETON YANG TIDAK TERPAKAI
}

\author{
Herlan Pratikto, Rekso Ajiono \\ Kadiri University
}

Email : herlan_pratikno@unik-kediri.ac.id, rekso_ajiono@unik-kediri.ac.id

\begin{abstract}
Concrete has many classifications and characteristics, from low-quality, medium to high-quality concrete. Along with the development of technology today many types of materials and mixtures are used. Additional materials include concrete that is not used. Tests of test objects in this study used a mixture of $10 \%, 15 \%, 20 \%$ and $25 \%$. The variation is carried out at the age of 7, 21, and 28 days with the parameters used are only compressive strength. The results showed that the average compressive strength of concrete in each variation was 10\% (22,155Mpa), 15\% (17,514 Mpa), 20\% (15,271 Mpa) and 25\% (12,714 Mpa). With the target of K300 compressive strength, the result is mixed substitution with a maximum compressive strength percentage of $10 \%(22,155 \mathrm{Mpa})$.
\end{abstract}

Keywords: Unused concrete, Compressive Strength

\section{PENDAHULUAN}

Beton merupakan campuran yang berisipasir, krikil/ batu pecah serta semen dan air yang sering di gunakan dalam berbagai macam bangunan konstruksi, beton berperan penting dalam pembangunan gedung mau pun jembatan. Beton sendiri memiliki berbagai kelebihan, salah satunya adalah beton mampu memikul beban tekan yang berat dibanding dengan bahan lainnya. Sifat yang paling penting dari suatu agregat (batu-batuan, kerikil, pasir dan lain-lain) ialah kekuatan hancur dan ketahanan terhadap beban tekan.(Candra \& Siswanto, 2018)

Berdasarkan kuat tekannya, mutu beton dibagi menjadi 3 jenis, yaitu beton mutu rendah (low strength concrete), beton mutu sedang (medium strength concrete) dan beton mutu tinggi (high strength concrete ) dimana beton merupakan pilihan yang paling tepat untuk membuat bangunan bertingkat tinggi. Penelitian yang di lakukan adalah dengan melakukan pecobaan pembuatan beton dengan memanfaatkan limbah beton yang sudah hancur sebagai campuran / pengganti batu pecah / kerikil pada umumnya. Pemanfaatan limbah itu sendiri bertujuan untuk mengetahui kualitas beton yang hal ini beton apakah memenuhi ketentuan syarat yang di berikan SNI. Limbah Beton yang sudah hancur merupakan salah satu limbah yang dihasilkan oleh pekerjaan beton yang salah atau pembongkaran beton di bangunan. Oleh karena itu, pada penelitian ini kami akan mencoba mengaplikasikan limbah beton yang 
sudah hancur tersebut sebagai bahan alternatif yang diharapkan dapat menghasilkan beton dengan mutu tinggi.

\section{METODE PENELITIAN}

\subsection{Kepustakaan}

Beton merupakan sebuah bahan bangunan yang terbuat dari kombinasi agregat dan pengikat semen. Bentuk paling umum dari beton adalah semen Portland, yang terdiri dari agregat mineral seperti kerikil, pasir, semen dan air. Biasanya dipercayai bahwa beton mengering setelah pencampuran dan peletakan pada suatu tempat. Sebenarnya, beton tidak menjadi padat karena air menguap, tetapi semen berhidrasi, mengelem komponen lain yang bersama dan pada akhirnya membentuk material berupa batu. Beton digunakan untuk membuat perkerasan jalan,struktur parkiran, struktur bangunan, jalan , pondasi, jembatan penyeberangan, dasar untuk pagar/gerbang, dan semen dalam bata atau tembok blok. Nama lama untuk beton adalah batu cair.

Dalam pekermbangan saat ini banyak sekali ditemukan beton model baru hasil modifikasi, seperti beton berkekuatan sangat tinggi, beton fiber,beton ringan, beton semprot, beton berkekuatan tinggi, beton mampat sendiri dll. Dan pada saat ini beton merupakan suatu bahan bangunan yang paling banyak digunakan di dunia. Menurut SNI 19742011 tes standar untuk kekuatan tekan beton dengan silinder sampel dengan diameter $15 \mathrm{~cm}$ dan tinggi $30 \mathrm{~cm}$ dihitung dengan membagi beban maksimum yang dicapai dengan luas permukaan sampel beton. (Limantara, Widodo, Winarto, Krisnawati, \& Mudjanarko, 2017). Secara sistematis dapat ditulis sebagai berikut:

$\mathrm{K}=\mathrm{P} / \mathrm{A}$

\section{Keterangan :}

$\mathrm{k}=$ Kuat tekan beton, $\mathrm{kg} / \mathrm{cm}^{2}$

$\mathrm{P}=$ Besar beban maksimum, $\mathrm{kg}$

$\mathrm{A}=$ luas penampang beton, $\mathrm{cm}^{2}$ 
Tabel 1 : Rasio Kuat Tekan Beton

\begin{tabular}{|c|c|}
\hline & \\
& \\
Umur (hari) & Rasio Kuat Tekan \\
\hline 3 & 0.40 \\
\hline 7 & 0.65 \\
\hline 14 & 0.88 \\
\hline 21 & 0.95 \\
\hline 28 & 1.00 \\
\hline 49 & 1.07 \\
\hline 90 & 1.20 \\
\hline 365 & 1.35 \\
\hline
\end{tabular}

Karena benda uji akan dibuat beberapa buah, kemungkinan besar hasil uji benda tersebut akan berbeda. Dan faktor perbedaan (Deviasi) sangat mempengaruhi dalam perhitungan besarnya nilai kuat tekan beton. Berikut ini Rumus Standar Deviasi :

$S d=\sqrt{\frac{\sum(X i-X i t)^{2}}{(n-1)}}$

Keterangan : 


$$
\begin{array}{lll}
\sum_{\mathrm{Xi}} & = & \text { Sigma (Penjumlahan) } \\
\mathrm{Xrt} & = & \text { Data Kuat Tekan dari Masing-masing Benda Uji (X1,X2..dst) } \\
\mathrm{n} & = & \text { Jumlah Kuat Tekan dari Rata-rata semua Benda Uji }
\end{array}
$$

Rumus Kuat Tekan Karakteristik (X) : X $=$ Xrt - (1,645 xSd)

\subsection{Metodologi Penelitian}

Penelitian yang akan dilakukan ini dilaksanakan di Laboraturium Jurusan Teknik Sipil Universitas Kadiri. Penelitian ini menggunakan benda uji kubus $15 \mathrm{~cm}, 15 \mathrm{~cm}, 15 \mathrm{~cm}$ sebanyak 6 benda uji dengan Variasi $10 \%, 15 \%, 20 \%$, dan 25\%. Langkah pembuatan campuran beton :

1. Menakar seluruh campuran yang dibutuhkan baik abgregat halus, semen, agregrat kasar (kerikildan beton yang tidak terpakai), air sesuai dengan mix design, untuk beton yang tidak terpakai campuran mengunakan Variasi $10 \%, 15 \%, 20 \%$, dan $25 \%$ di setiap campurannya.

2. Menyiapkan air (sesuai Job Mix) dalam moolen, kemudian mengaduk hingga campuran merata.

3. Memasukkan semen kedalam TM Moolen dan Mix dengan air.

4. Memasukkan Pasir dan Kerikil sesuai volume dalam Job Mix, memutar TM Moolen \pm 15 menit agar campuran merata. Agar beton merata, molen dibolak-balik sesuai kemiringan tertentu,tetapi jangan sampai tumpah coran atau isi dalam moolen.

5. Menuangkan campuran beton diatas loyang untuk pengujian nilai slump.

6. Mengisikan campuran beton ke dalam Kubus untuk dicetak sebagai benda uji (sampel).

Tahap analisa data dan pembahasan, pada tahap selanjutnya data yang diperoleh setelah penelitian yang dilaksanakan di laboratorium. Analisa data menggunakan metode penelitian dengan cara pendekatan kualitatif, akan mendapatkan suatu hasil dan kesimpulan dengan menginterpretasi tabel, grafik, dan angka yang didapat dari hasil penelitian. 


\section{PEMBAHASAN}

Hasil dari penelitian campuran beton menggunakan bahan penambah beton yang tidak terpakai dituangkan dalam tabel.

Tabel 2 : Rata-rata Uji Kuat Tekan Beton

\begin{tabular}{|c|c|c|c|c|c|c|c|}
\hline \multirow{2}{*}{ No } & \multirow{2}{*}{ Faktor } & \multirow{2}{*}{ Umur } & \multicolumn{2}{|c|}{ Hasil Tes Kuat Tekan } & \multirow{2}{*}{$\begin{array}{l}\text { Faktor } \\
\text { Umur }\end{array}$} & \multirow{2}{*}{$\begin{array}{c}\text { Hasil } \\
\text { Konversi } \\
\text { Kuat } \\
\text { Tekan }\end{array}$} & \multirow{2}{*}{$\begin{array}{c}\text { Rata- } \\
\text { Rata } \\
\text { Kuat } \\
\text { Tekan } \\
\text { (Mpa) }\end{array}$} \\
\hline & & & Ton & $\mathrm{Mpa}$ & & & \\
\hline 1 & \multirow{6}{*}{$10 \%$} & 7 & 45 & 16,6 & 0,65 & 25,538 & \multirow{6}{*}{22,155} \\
\hline 2 & & 7 & 45 & 16,6 & 0,65 & 35,538 & \\
\hline 3 & & 14 & 47 & 21,027 & 0,95 & 22,133 & \\
\hline 4 & & 14 & 55 & 20,289 & 0,95 & 21,357 & \\
\hline 5 & & 28 & 53 & 19,551 & 1 & 19,551 & \\
\hline 6 & & 28 & 51 & 18,813 & 1 & 18,813 & \\
\hline 7 & \multirow{6}{*}{$15 \%$} & 7 & 35 & 12,911 & 0,65 & 19,863 & \multirow{6}{*}{17,514} \\
\hline 8 & & 7 & 36 & 13,28 & 0,65 & 20,431 & \\
\hline 9 & & 14 & 42 & 15,493 & 0,95 & 16,309 & \\
\hline 10 & & 14 & 46 & 16,969 & 0,95 & 17,862 & \\
\hline 11 & & 28 & 43 & 15,8862 & 1 & 25,862 & \\
\hline 12 & & 28 & 40 & 14,756 & 1 & 14,756 & \\
\hline 13 & \multirow{6}{*}{$20 \%$} & 7 & 30 & 11,067 & 0,65 & 17,026 & \multirow{6}{*}{15,271} \\
\hline 14 & & 7 & 32 & 11,804 & 0,65 & 18,161 & \\
\hline 15 & & 14 & 39 & 14,387 & 0,95 & 15,144 & \\
\hline 16 & & 14 & 37 & 13,649 & 0,95 & 14,367 & \\
\hline 17 & & 28 & 35 & 12,911 & 1 & 12,911 & \\
\hline 18 & & 28 & 38 & 14,018 & 1 & 14,018 & \\
\hline 19 & \multirow{6}{*}{$25 \%$} & 7 & 25 & 9,222 & 0,65 & 14,188 & \multirow{6}{*}{12,714} \\
\hline 20 & & 7 & 28 & 10,329 & 0,65 & 15,891 & \\
\hline 21 & & 14 & 32 & 11,804 & 0,95 & 12,426 & \\
\hline 22 & & 14 & 30 & 11,067 & 0,95 & 11,649 & \\
\hline 23 & & 28 & 30 & 11,067 & 1 & 11,067 & \\
\hline 24 & & 28 & 30 & 11,067 & 1 & 11,067 & \\
\hline
\end{tabular}

(sumber; Data diolah) 


\section{KESIMPULAN dan SARAN}

\subsection{Kesimpulan}

Dari seluruh pengujian, untuk analisa dan pembahasan yangsudah dilakukan dalam penelitian tersebut yang telah dilakukan di Laboratorium Beton Fakultas Teknik Universitas Kadiri maka dapat diambil kesimpulan sebagai berikut :

1. Kuat tekan beton yang di hasilkan dari rata-rata campuran bahan limbah beton yang sudah tidak terpakai 16,977 Mpa.

2. Prosentase daya serap yang dihasilkan $6,181 \%$.

3. Campuran beton yang paling optimum adalah $10 \%$ karena kuat tekannya sangat kuat.

\subsection{Saran}

Berdasarkan hasil penelitian tersebut yang sudah dilaksanakan maka sebagai bahan pertimbangan kedepan, diajukan beberapa saran sebagai berikut:

1. Perlu dilakukan penelitian lebih lanjut dengan variasi lain lagi untuk penambahan limbah beton yang tidak terpakai, untuk mendapatkan nilai campuran yang lebih akurat.

2. Perhatikan proses pemadatan pada saat pembuatan benda uji beton dengan menggunakan vibrator agar hasil bisa semaksimal mungkin karena menghindari udara dalam beton dan beton bisa lebih padat . 


\section{DAFTAR PUSTAKA}

[1] Departemen Pekerjaan Umum, 2011, Cara Uji Kuat Tekan Beton dengan

[2] Departemen Pekerjaan Umum, 2002, Tata Cara Perhitungan Struktur BetonUntuk Bangunan Gedung dengan Standar SK SNI 03-2487-2002, BadanStandarisasi Nasional.

[3] Departemen Pekerjaan Umum, 2008, Cara Uji Berat Isi Beton Ringan Struktural SNI 3402-2008, Badan Standarisasi Nasional

[4] Departemen Pekerjaan Umum, 2013, Tata Cara Perhitungan Struktur BetonUntuk Bangunan Gedung dengan Standar SK SNI 03-2487-2013, BadanStandarisasi Nasional

[5] JIS A 1148, 2010, Method of Test for Resistance of Concrete to Freeze andThawing, Japan Concrete Institute.

[6] “Makalah tentang Semen Portland". 16 Mei 2018. http://ariefrvi. blogspot.co.id/2013/07/ makalah-tentang-semen-portland.html.

[7] Mulyono, T. 2004,Teknologo Beton,Andi,Yogyakarta

[8] Mustaqim, M. I., Marliansyah, J., Rahmi, A., Sipil, M. T., Teknik, F., Pengaraian, Pradana, S. A. (2013). Tugas akhir, (Pembimbing I), 2506.

[9] SNI 15-2049-2004.Jakarta: “Semen Portland.” Departemen Pekerjaan Umum. Badan Standardisasi Nasional. (2004).

[10] SNI 1974:2011, Cara uji kuat tekan beton dengan benda uji silinder.

[11] SNI 2493:2011, Tata cara pembuatan dan perawatan benda uji di laboraturium.

[12] SNI-2847-2013. Persyaratan beton Sstruktural untuk bangunan gedung.

[13] SNI 1972. (2008). Cara Uji Slump Beton. Badan Standar Nasional Indonesia. “Cara menghitung Standar Deviasi”. 20 April 2018. https://proyeksipil.blogspot. 
co.id/2013/05/cara-menghitung-standard- deviasi dan.html.

[14] SNI 03-0691-1996.(1996). Persyaratan Mutu Paving Plock. Badan Standar Nasional. 